\title{
Histoire vraie... ou le récit d'Alice
}

\author{
Julia Vecsey \\ Dr méd., membre de la FMH
}

\author{
Nicolas, mon mari, le papa de mes 2 filles, (âgées l'une de quatre ans, l'autre tout \\ juste de 4 mois), était alors en permission exceptionnelle de la glaciale prison où \\ il était détenu pour d'obscures raisons politiques et arbitraires. N'était-il pas un \\ «ennemi du peuple»? Et il devait regagner sa geôle, à moins que...
}

Notre départ de Budapest s'est effectué en train (on avait dit à notre fille aînée que la famille se rendait à la campagne pour tuer le cochon, afin qu'elle ait quelque chose de crédible à dire en cas d'interrogatoire!)

Nous sommes arrivés près de la frontière grâce à différents moyens de locomotion, accompagnés de ma propre mère, et c'est là que, dans la confusion la plus totale, nous avons dû nous séparer pour de bon, elle et moi, sans un regard, sans un adieu... je ne devais plus jamais la revoir... Elle qui avait réalisé l'ultime sacrifice de se séparer de son propre fils en nous le confiant.

\section{Après plusieurs heures de voyage, nous} croyions être à la frontière, mais pas du tout!

Mon frère avait 14 ans, l'âge de la fougue et de l'idéalisme. Précisément son idéal de justice l'avait conduit aux barricades, et les chars russes l'avaient par miracle épargné, mais pour Vivre, nos parents n'avaient pas d'autre choix que de nous le confier, afin de lui donner une liberté interdite de l'autre côté du rideau de fer. Après plusieurs heures de voyage, nous croyions être à la frontière, mais pas du tout! Dans une terre lourde et boueuse, nous devions faire des efforts surhumains pour progresser, à pied bien sûr. A bout de souffle, au bout de plusieurs heures d'efforts, nous n'en pouvions plus, il fallait qu'on s'arrête. C'est à ce moment-là que dans l'obscurité deux maisons sont apparues, toutes deux étaient éclairées; laquelle choisir? C'était pile ou face.

$\mathrm{Au}$ hasard, nous nous sommes dirigés vers la première, et lorsque, nous sommes arrivés à la porte, c'est une famille de paysans qui nous a accueillis:

Heureusement, nous disent-ils que vous n'êtes pas allés dans l'autre maison, car elle est occupée par des gardes-frontières russes!

La paysanne m'a proposé de m'étendre sur un lit, dont le confort était divin et inoubliable: j’avais caché à tous que j'avais $40^{\circ}$ de température (complications secon- daires à ma maternité relativement récente) pour ne pas retarder encore notre départ.

Pendant ce temps, le paysan, auquel nous avions offert notre dernière bouteille de Pàlinka (eau-de-vie), est allé l'offrir aux gardes-frontières voisins, dans l'intention de les soudoyer. A son retour, la voie était donc libre et il nous a accompagnés jusqu'à l'Autriche, et assuré notre fuite.

A ce moment-là dans la nuit, nous entendîmes des coups de feu qui nous forcèrent à nous coucher par terre; notre cadette était endormie dans la corbeille, un peu assommée par les somnifères administrés pour que ses pleurs éventuels ne viennent pas ruiner la discrétion de l'épopée. Quelques instants plus tard, le silence revenu, nous avons pu redémarrer. Après quelques pas, nous avons réalisé que la corbeille du bébé était légère et vide, car notre fille avait roulé par terre!

Demi-tour;

J'ai vécu alors les secondes les plus longues de ma vie jusqu'aux retrouvailles avec Julia, à terre, mais paisiblement blottie dans les bras de Morphée.

Nous avons encore marché, et toujours marché, guidés par la lueur des phares autrichiens.

Nous avons encore marché, et toujours marché, guidés par la lueur des phares autrichiens; l'évasion a été couronnée de succès, et nous avons été accueillis à bras ouverts par des étudiants autrichiens, qui ont dirigé aussitôt les hommes d'un côté et les femmes et les enfants de l'autre. On m'a aidée à monter dans une ambulance avec mes filles, et j'ai vu avec angoisse mon mari et mon frère s'éloigner à pied.

Par les fenêtres de l'ambulance, je voyais le paysage défiler: les décorations de Noël rendaient irréelles les façades, le spectacle des paysannes en Vespa appartenait à un autre monde!

Une pensée curieuse a traversé mon esprit tout en roulant dans l'ambulance: que de toits, que de maisons, 
que de foyers abritant autant de lits pour tous ces habitants, et nous, nous n'avions plus rien, plus de maison, plus de lit, plus de toit...

\section{Arrivée au camp de réfugiés de Sankt Pölten, débarquement des blessés.}

Arrivée au camp de réfugiés de Sankt Pölten, débarquement des blessés. Je ferme la marche avec la corbeille sur laquelle se pose le regard plein de pitié des passants, tant le sommeil de Julia est profond et son teint livide. Ils la croient morte, et ne soupçonnent pas que quelques minutes plus tard, grâce au lait maternel, la couleur reviendra aux joues du bébé, et le sourire à ses lèvres. Puis retrouvailles avec les hommes de la famille.

Après une courte nuit au camp, nous téléphonons à Genève (bien sûr en PCV, mais c'était une précaution inutile tant la générosité des Autrichiens était remarquable!), et apprenons que ma belle-sœur et son mari suisse ont déposé de l'argent pour nous à l'ambassade de Suisse à Vienne. Ils nous attendent chez eux, à Genève.

Mais c'était sans compter sur les dimanche et jours fériés (le 8 décembre, on célèbre l'Immaculée Conception, jour férié en Autriche, et à l'ambassade suisse, nous avons donc trouvé porte close... Et ça devait durer une semaine...)!

Dans une ville inconnue, sans abri, sans argent, que faire? Où dormir? Où manger? C'est alors que je me suis souvenue d'une religieuse du Sacré-Cœur, membre de l'ordre que j'avais fréquenté à Budapest, comme plusieurs générations de ma famille avant moi. Nous nous sommes donc rendus à l'ordre du Sacré-Cœur à Vienne, demandant Mère Jàrmai; miracle, elle est là, me reconnaît, elle me prend dans ses bras, me réconforte et accueille les miens.

Par malheur, l'école où se trouvait le Sacré-Cœur était pleine à craquer, débordante de réfugiés; impossible de nous loger. C'est alors que la Mère disparaît quelques instants, avant de revenir avec une enveloppe contenant des billets nous permettant d'aller loger à l'hôtel. Après avoir baigné mes deux filles, après que mon mari et mon frère aient pris leur bain, je m’apprêtais enfin à me laver moi aussi; c'est alors que l'hôtelier est venu frapper à la porte, et a demandé impatiemment combien de bains nous comptions encore prendre! En guise de réponse, j'ai explosé, et tout penaud, il a tourné les talons.

\section{Après quelques jours viennois, un train nous} emporte vers notre destination à croix blanche!

Après quelques jours viennois, un train nous emporte vers notre destination à croix blanche!

Lorsque nous avons atteint la Suisse, nous avons été merveilleusement accueillis, et la générosité de tous, membres de notre famille, amis de celle-ci, mais aussi de parfaits inconnus nous a profondément touchés, réchauffé le cœur. Grâce à tous, nous avons pu prendre un nouveau départ dans la vie. Merci.

Propos recueillis par Julia Vecsey 